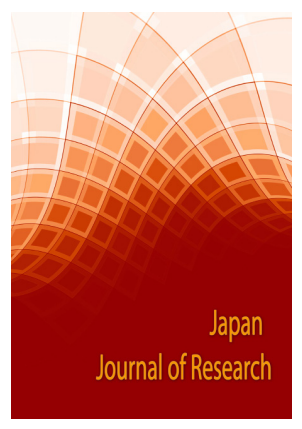

Correspondence

Maria Lúcia D’Arbo Alves

Medical Course of Ribeirão Preto University (UNAERP), Ribeirão Preto, São Paulo, Brazil

E-mail:mldarbo@bol.com.br

\footnotetext{
- Received Date: May 05, 2020;

- Accepted Date: May 14, 2020;

- Publication Date: May 28; 2020.
}

\section{Keywords}

Thyroiditis, Chronic Thyroiditis, Lymphocytic Thyroiditis, Hashimoto Thyroiditis, Hypothyroidism.

\section{Copyright}

(C) 2020 Science Excel. This is an openaccess article distributed under the terms of the Creative Commons Attribution 4.0 International license.

\title{
Clinical-Laboratory Evaluation of a Group of Patients with Hashimoto Thyroiditis
}

\author{
Maria Lúcia D'Arbo Alves ${ }^{1 *}$ and Manoel Henrique Cintra Gabarra ${ }^{2}$ \\ 'Medical Course of Ribeirão Preto University (UNAERP), Ribeirão Preto, São Paulo, Brazil. \\ ${ }^{2}$ Engeneering Course of Ribeirão Preto University (UNAERP), Ribeirão Preto, São Paulo, Brazil.
}

\begin{abstract}
Chronic lymphocytic thyroiditis (or chronic thyroiditis, or Hashimoto thyroiditis - HT) was first described in 1992 in Germany by the Japanese pathologist Hakuru Hashimoto as a new disease called lymphomatous struma. Today it represents the most frequent cause of hypothyroidism and goiter in the US and in areas of iodine sufficiency. It is the main cause of goiter in children and young adults and of idiopathic mixedema. The most important auto antibodies are antithyroglobulin (Anti-TG), antithyroperoxidase (Anti-TPO) and TSH receptor antibody blocker (TRAB). In the initial phase Anti-TG is markedly elevated while Anti-TPO is only mildly elevated. Anti-TG may disappear, but Anti-TPO continues to be positive for many years. Its pathogenesis has not been fully clarified. The estimate is that the pathogenesis of this immune disease is due genetic factors in 70 to $80 \%$ of cases and to environmental factors in 20 to $30 \%$ of cases. The study was conducted on 399 patients, 336 women (87.2\%) and 63 men (12.8\%), ranging in age from 11 to 95 years. The predominant age ranges were 20 to 70 years for women and 30 to 60 years for men. Blood samples were obtained for the determination of TSH, T4L, T3L, thyroglobulin, and anti-TPO, anti-thyroglobulin and TSH receptor (TRAB) antibodies by chemiluminescence. Anti-TPO and anti-TG autoantibody values were higher in Anti-TPO-positive and AntiTG -negative: Type 1 thyroiditis; and in Anti-TPO-negative and AntiTG - positive: Type 2 thyroiditis; and in Anti-TPO-positive and antiTG - positive: Type 3 thyroiditis; and in Anti-TPO-negative and AntiTG -negative: Type 4 thyroiditis. Autoantibody expression was similar in men and women, with predominance of type $4>$ type $3>$ type $2>$ type 1 when considering the oldest age of each sex ( 95 years for women and 85 years for men). When considering the youngest age studied, the following results were obtained: type $2>$ type $4>$ type $1>$ type 3 for women and type $3>$ type $1>$ type 4 > type 2 for men.
\end{abstract}

\section{Introduction}

Chronic lymphocytic thyroiditis (or chronic thyroiditis, or Hashimoto thyroiditis - HT) was first described in 1992 in Germany by the Japanese pathologist Hakuru Hashimoto as a new disease called lymphomatous struma [1] Today it represents the most frequent cause of hypothyroidism and goiter in the US and in areas of iodine sufficiency. It is the main cause of goiter in children and young adults and of idiopathic mixedema, the final stage of HT with total destruction of the gland [2-5].

HT is an organ-specific immunological disorder in which the lymphocytes are sensitized against thyroid antigens, the most important ones being antithyroglobulin (Anti-TG), antithyroperoxidase (Anti-TPO) and TSH receptor antibody blocker (TRAB). In the initial phase Anti-TG is markedly elevated while AntiTPO is only mildly elevated. Anti-TG may disappear, but Anti-TPO continues to be positive for many years. The TSH antibody blocker can be found in patients with atrophic thyroiditis and, more rarely, in mixedema [6-8]

The physiopathology of HT involves a marked infiltration of the thyroid gland, with destruction of its normal architecture. Lymphoid follicles and germinative centers are formed and the typical epithelium of the gland is increased, with an eosinophilic cytoplams laden with mitochondria (Hürtle cells). Failure of the gland causes a reduction of thyroid hormones (T3 and T4) and an increase of thyrotrpin hormone (TSH) which may initially maintain appropriate hormone synthesis with increased thyroid volume (goiter), but later progress to failure, with the onset of clinical hypothyroidism with or without goiter [9].

HT is part of the spectrum of autoimmune thyroid disease ranging from Graves disease to idiopathic mixedema. It has a familial component and may be associated with other forms of autoimmune diseases such as pernicious anemia, adrenocortical insufficieny, idiopathic hypoparathyroidism, myasthenia gravis, and vitiligo. It may also be part of polygladular autoimmune syndrome or Schimidt syndrome (HT, idiopathic adrenal insufficiency, and type 1 diabetes mellitus) [10-13].

Laboratory analysis reveals multiple defects of iodine metabolism, with radioactive iodine uptake (RAIU) being increased, normal or reduced, and accompanied by elevated TSH in the last case $[14,15]$. 
The most characteristic laboratory finding for this disease is the presence of plasma antibodies against thyroid antigens. Anti-TPO and Anti-TG antibodies are usually increased, fine needle aspiration biopsy (FNAB) reveals lymphocyte infiltration, and Hürtle cells may be positive. The presence of these autoantibodies and of a lymphocyte infiltrate in an FNAB differentiate this enlargement of the gland induced by HT from other types of goiter $[6,8,11,14,15]$.

The world prevalence of HT is $0.3-1.5 / 1000$ individuals and is ten time more frequent among females, with incidence peaking between 40 and 60 years of age $[10-13,16]$.

A population study conducted on a Japanese-Brazilian community detected a prevalence of Anti-TPO and Anti-TG positivity of $11.6 \%$ and $13.6 \%$ among women older than 30 years, with the presence of 1 and $8.9 \%$ frank and subclinical hypothyroidism, respectively, in women older than 60 years [17].

The pathogenesis of HT or of all other autoimmune thyroid diseases has not been fully clarified. It appears to result from the interaction of genetic susceptibility factors contributing to 70 to $80 \%$ of cases, and of epigenetic and environmental triggering factors contributing to 20 to $30 \%$ of cases [16-19].

The risk of HT is increased among the siblings of individuals with the condition and shows more concordance in monozygous than in heterozygous twins. The HLA-DR locus in chromosome $6 \mathrm{p} 21$ seems to play an important role in the pathogenesis of HT. It has been demonstrated that other haplotypes are associated with greater susceptibility to HT, while still others may have a protective effect. Identified and confirmed genes involved in the immunomodulation for susceptibility to HT are CTLA4, the phosphatase protein gene-22 (PTPN22), CD40. CD25, and FOXP3 [20,21].

Identified risk factors for Graves disease (pregnancy, medications, sex, age, infection, irradiation) are also applicable to HT [22,23]. Age is important in the pathogenesis of HT, with the prevalence of thyroid autoantibodies (TSAb) increasing from $9.8 \%$ to $15 \%$ among individuals older than 60 years. Age is supposed to increase exposure to environmental agents, causing changes in immunomodulation [16-19].

The up to ten-fold higher prevalence among women suggests that chromosome X may be involved and that estrogen would have an exacerbating effect on the immune system, while testosterone would have a protective effect. The use of oral contraceptives may also be related to cell apoptosis [18-21].

An increased prevalence of HT has been reported in the presence of increased iodine intake, this being the main factor responsible for the progressive increase of HT over the last decades. Greater iodine consumption by susceptible individuals may increase the intrathyroid quantity of Th17 lymphocytes, inhibiting the development of regulatory $\mathrm{T}$ cells, and abnormal expression of the TRAL cytokine (tumor necrosis factor) may induce thyrocyte apoptosis by the induction of ligands and the destruction of gland parenchyma $[16,17]$.

The deficiency of selenium, an essential micronutrient for the synthesis of selenoproteins with an important role in TH synthesis, metabolism and action, is associated with goiter and the thyroid hypoechogenicity typical of HT and its supplementation causes changes in the immune response and reduction of Anti-TPO titers and of hypoechogenicity in patients with autoimmune thyroiditis [19-22].

Treatment of these patients with interleukin 2 (IC-2) or interferon- $\alpha$ may precipitate the onset of autoimmune thyroid disease (AITD) Graves or HT [22].

Persons with low vitamin D titers have a higher prevalence of HT due to a still unclarified mechanism [20]. Accidental or therapeutic exposure to radiation can induce the onset of antithyroid antibodies or AITD [20]. Evidence of the triggering of AITD related to seasonality, geographic variation and positive serology for a recent bacterial or viral infection suggests a role of these factors in HT. However, the only infectious agent directly associated with an increased risk of AITD due to an unknown mechanism is the hepatitis C virus (HCV) [19]. Cytohistologically, HT is characterized by lymphocyte, plasmocyte and macrophage infiltration into the thyroid parenchyma, with varying degrees of atrophy and fibrosis, small or hyperplastic follicular cells with tall columnar epithelium, and characteristic Hürtle or Askanazy cells (large cells with hyperchromatic and vacuolized nuclei and eosinophilic cytoplasm) [4,22].

Clinically, HT occurs with goiter as the most common form in $90 \%$ of patients, and without goiter in about $10 \%$ of patients, representing the final stage of the disease $[4,19,22]$.

\section{Patients and Methods}

The study was conducted on 399 patients, 336 women (87.2\%) and 63 men (12.8\%), ranging in age from 11 to 95 years (Ethics CommitteePlataforma Brasil 6268216300005498). Blood samples were obtained for the determination of TSH, T4L, T3L, thyroglobulin, and antiTPO, anti-thyroglobulin and TSH receptor (TRAB) antibodies by chemiluminescence.

The normal ranges for each exam were as follows: $\mathrm{TSH}=0.27-5.0$ $\mathrm{IU} / \mathrm{L}$; free T4 $=0.8-1.9 \mathrm{ng} / \mathrm{dl}$; free T3 $=2.0-4.4 \mathrm{ng} / \mathrm{dl}$; thyroglobulin $=$ 1.4-75 ng/ml; antithyroperoxidase antibody (Anti TPO) < $34 \mathrm{IU} / \mathrm{ml}$; antithyroglobulin antibody (Anti TG) $<115 \mathrm{IU} / \mathrm{ml}$; and TRAB $<0.55$ IU/L, determined in cases of suppressed TSH and/or increased free T4 and/or T3 levels [14,15].

For the analysis of antibody expression, the thyroiditis were classified into 4 types:: type $1=$ Anti-TPO positive $(+)$ and Anti-TG negative (-); type 2 = Anti-TPO negative (-) and Anti-TG positive (+); Type 3 = Anti-TPO and Anti-TG positive 9+); type $4=$ Anti-TPO and AntiTG negative (-). The results obtained were crossed with the following data: sex, age, predominant age range, TSH, T4L and thyroglobulin findings, as well as ultrasound findings, and compared in order to look for specific characteristics of each group that might determine differential expression of each of these antibodies.

Ultrasound exams were performed with an instrument equipped with a multifocal linear transducer and analyzed in terms of the following aspects: presence of nodularity; presence of calcifications, evaluation of the risk of malignancy using the TIRADS classification with values higher than 4 (indication of FNAB); presence of gland hypoechogenicity (an ultrasound sign of thyroiditis); presence of regular contours; presence of single, multiple, solid, cystic, microcystic, solid and cystic nodules in the same gland, presence of pseudonodularity (an ultrasound finding in a gland with HT); evaluation of vascularization (which may be increased in inflammatory processes).

The results are reported as mean and standard deviation and were analyzed statistically by the ANOVA test.

\section{Results}

The results obtained for the various parameters studied are listed in Tables 1-11 and in Figure 1.

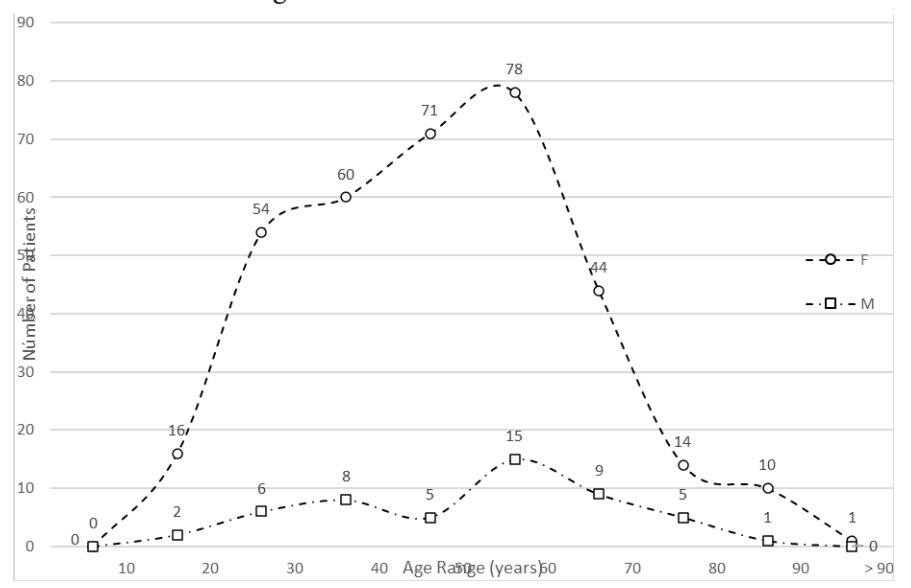

Figure 1: Patient distribution (number) according to sex (Female, Male) and age (years). 
The study was conducted on 399 patients, 336 women (87.2\%) and 63 men (12.8\%), ranging in age from 11 to 95 years (mean: 46.5 years) for women and from 14 to 85 years (mean: 49.6 years) for men (Tables 1 and 2, Figure 1).

The predominant age ranges were 20 to 70 years for women and 30 to 60 years for men (Tables 4 and 5).

Anti-TPO and anti-TG autoantibody values were higher in AntiTPO-positive and AntiTG -negative: Type 1 thyroiditis; and in AntiTPO-negative and AntiTG - positive: Type 2 thyroiditis; and in Anti-TPO-positive and antiTG - positive: Type 3 thyroiditis; and in Anti-TPO-negative and AntiTG -negative: Type 4 thyroiditis (Tables 3,6 and 7) [14,15].

Autoantibody expression was similar in men and women, with predominance of type $4>$ type $3>$ type $2>$ type 1 when considering the oldest age of each sex (95 years for women and 85 years for men). When considering the youngest age studied, the following results were obtained: type $2>$ type $4>$ type $1>$ type 3 for women and type 3 $>$ type $1>$ type $4>$ type 2 for men (Tables 6 and 7 ).

The highest TSH values expressed (IU/L) were: type 3 (136.8) > type $4(71.1)>$ type $2(67.64)$ and type $1(45)$ and the lowest were: type 3 $(0.5)<$ type $1(0.61)<$ type $2(0.83)<$ type $4(5.01)$. The mean TSH values expressed were: type $2(6.1)<$ type $1(6.5)<$ type $3(10.4)<$ type 4 (13.8). The TSH results in each of the 4 types of thyroiditis studied according to autoantibody expression were statistically significant $(\mathrm{p}=0.0043)$.

Free T4 values (ng/dl) were as follows: type $3(4.39)>$ type $1(2.45)>$ type 2 (1.5), type 4 (1.48). The lowest free T4 values expressed (ng/dl) were: type $3(0.06)<$ type $1(0.16)<$ type $4(0.37)<$ type $2(0.58)$.

Thyroglobulin expression $(\mathrm{ng} / \mathrm{dl})$ was as follows: highest values $=$ type $1(500)>$ type $3(348)>$ type $4(302)>$ type $2(259)$; lowest values: type $3(0.3)<$ type $1(0.8)<$ type $4(1.0)<$ type $2(1.0)$. The mean values were: type $2(29)<$ type $3(42)<$ type $4(56.6)<$ type $1(62.6)$, with a nonsignificant difference between results $(\mathrm{p}=0.0553)$.

Patients with HT were divided into the following groups according to the type of autoantibodies they showed: type $1=$ Anti-TPO positive and Anti-TG negative; type $2=$ Anti-TPO negative and Anti-TG positive; type 3 = Anti-TPO and Anti -positive; type $4=$ Anti-TPO and Anti-TG negative. The following frequencies of occurrence were detected: type $1=31.07 \%$, type $2=2.01 \%$, type $3=42.70 \%$, and type $4=2.61 \%$.

Ultrasound examination was performed in order to assess the size and aspect of the gland, the presence of nodules/cysts, and the number and association of these lesions.

The finding of multinodularity was statistically significant $(\mathrm{p}=0.001)$, sequentially occurring as follows: type 2 , type 1 , type 3 and type 4 .

Discussion

Hashimoto thyroiditis or lymphocytic thyroiditis is the most common cause of acquired hypothyroidism.

Its pathogenesis has not been fully clarified. The estimate is that the pathogenesis of this immune disease is due genetic factors in 70 to $80 \%$ of cases and to environmental factors in 20 to $30 \%$ of cases $[18,19]$.

HT is more frequent among the siblings of affected individuals and has a high rate of concordance in monozygous twins. HT has been associated with the HLA-DR9 system in the Chinese population and HT with goiter has been associated with HLA-DR5. The CTLA-4 molecule is the main negative regulator of protein B7 (expressed in the antigen-presenting cell) in response to the costoimulator protein CD28.

Mutations of the CTL4 gene may result in exaggerated activation of $\mathrm{T}$ lymphocytes and the development of autoimmunity [18-21]. The pathogenesis of autoimmunity has not been fully clarified. The estimate is that genetic factors make a 70 to $80 \%$ contribution and environmental factors a 20 to $30 \%$ contribution to the pathogenesis of autoimmune disease [22-24].

In HT, the levels of free T4 and TSH may be compatible with hypothyroidism, euthyroidism or hyperthyroidism depending on the phase analyzed and the immunological status of the patient at the time of study [18].

Subclinical hypothyroidism (elevated TSH with normal T3 and T4) is a common finding and its rate progression to frank hypothyroidism is 3 to $55 \%$ per year, especially among women older than 60 years [18]. Female sex predominated in the present study, with younger women than men being affected. Estrogen may have played a role in this higher prevalence among young women, with their younger affected age possibly being related to the higher estrogen production associated with greater sensitization in young females, who would respond more intensely to the autoimmune stimulus $[18,23]$.

Mean age was 30 years for women and 43 years for men. The most prevalent age range was 30-65 years for women and 50-70 years for men $[18,23,24]$.

In the present study, the prevalence of thyroiditis was higher among women and among younger women. It is possible that estrogen, present at higher levels in this age range, may act as a mediator of a more marked immune response in this age range. Men may have a lower prevalence of HT because of their higher testosterone and lower estrogen levels, which would protect the male thyroid. The age range of men was close to that of women, with no statistically significant difference $[18,19,25]$.

However, these AITD a contradict the information that younger patients may have less elevated thyroid autoantibody titers, whereas older patients may have higher titers by having been exposed to autoimmune aggression for a longer period of time $[19,20]$.

The highest TSH values were $13.8 \mathrm{IU} / \mathrm{L}$ in type $4,10.4$ in type 3 , 6.5 in type 1 , and 6.1 in type 22 and were statistically significant $(\mathrm{p}=0.0043)$. They also suggest that type $4 \mathrm{HT}$, with the absence of detectable autoantibodies, may correspond to a greater autoimmune aggression to the gland which would no longer express antigens able to stimulate the immune system, or may correspond to the type of atrophic thyroiditis due to the TSH receptor blocker antibody, which was not determined here due to the unavailability of a satisfactory method for its determination $[26,27]$.

If the antithyroperoxidase antibody is the autoantibody more frequently present in HT, it may also be the first to arise and may be related to a more marked immune response. The antithyroglobulin antibody may arise concomitantly with the anti-TPO antibody, but may also be the only antibody present in this autoimmune process. It has been reported that the antithyroglobulin antibody is the first to disappear $[16,17]$. It is also possible that the third autoantibody (TSH receptor blocker) is responsible, by itself, for this aggression and that the technique used here was not the most appropriate for its detection.

The mean free T4 levels were 1.06 in type 1, 1.10 in type 2, 1.05 in type 3 , and 0.9884 in type 4 . These AITD a were not statistically significant (free T4 $\mathrm{p}=0.292$ ) and were compatible with the TSH values obtained in the present study $[18,19]$.

The TG values observed were representative, with higher mean values in types 1 and 4, followed by types 2 and 3 . This result may suggest that the anti-TPO antibody, the first to appear, may be more aggressive than the antithyroglobulin antibody, which is the first to disappear $[12,18,19,23]$.

Several possible combinations of changes in thyroid structure (diffuse goiter, nodular goiter with single or multiple nodules, cysts, heterogeneity) were observed, although without statistical significance (Table 11) [28,29].

The only statistically significant structural change was the presence of a solid nodule in association with a cystic nodule in the same gland ( $\mathrm{p}<0.001)$, more frequently detected in type 2 (anti-TPO negative and anti-TG positive). We speculate whether this autoantibody association might be the cause of this morphological finding, which was not observed in type 3 thyroiditis (with both autoantibodies positive) because Anti-TPO may reduce the expression of Anti-TG in the same gland. In the present study, no patient showed association of HT with malignant neoplasias, even among those with thyroid nodules submitted to FNAB [30,31]. 


\begin{tabular}{|c|c|c|}
\hline Sex & N & \% \\
\hline Female & 348 & $87.2 \%$ \\
\hline Male & 51 & $12.8 \%$ \\
\hline Total & 399 & $100 \%$ \\
\hline
\end{tabular}

Table 1: Prevalence of female and male sex among the 399 patients with Hashimoto thyroiditis studied. $\mathrm{N}=$ Number of patients.

\begin{tabular}{|c|c|c|c|c|}
\hline & \multicolumn{4}{|c|}{ Age (years) } \\
\hline Sex & Mean & Standard deviation & Minimum & Maximum \\
\hline Female & 46.6 & 16.4 & 11 & 95 \\
\hline Male & 49.6 & 17.5 & 14 & 85 \\
\hline
\end{tabular}

Table 2: Age range in years (mean, standard deviation, minimum amd maximum) according to sex of the patients with Hashimoto thyroiditis studied.

\begin{tabular}{|c|c|c|c|c|c|}
\hline & \multicolumn{5}{|c|}{ Type of autoantibody expressed } \\
\hline SEX & $\mathbf{1}$ & $\mathbf{2}$ & $\mathbf{3}$ & $\mathbf{4}$ & Total \\
\hline Female & 108 & 77 & 134 & 29 & 348 \\
\hline Male & 16 & 8 & 16 & 11 & 51 \\
\hline Total & 124 & 85 & 150 & 40 & 399 \\
\hline
\end{tabular}

Table 3: Distribution of the 4 types of lymphocytic thyroiditis according to sex.

Type1. Only Anti-TPO+ antibody; Type2. Only Anti-TG+ antibody; Type3. Anti-TPO and Anti-TG (+); Type 4. Anti-TPO and Anti-TG (-); Anti-TPO= Anti-thyroperoxidase antibody $/$ Anti-TG $=$ Antityroglobulin antibody.

\begin{tabular}{|c|c|c|c|c|c|c|c|c|c|}
\hline & \multicolumn{10}{|c|}{ Age (age range) } \\
\hline Type & $\begin{array}{c}>=\mathbf{1 0} \\
\text { and } \\
<\mathbf{2 0}\end{array}$ & $\begin{array}{c}>=\mathbf{2 0} \\
\text { and } \\
<\mathbf{3 0}\end{array}$ & $\begin{array}{c}>=\mathbf{3 0} \\
\text { and } \\
<\mathbf{4 0}\end{array}$ & $\begin{array}{c}>=\mathbf{4 0} \\
\text { and } \\
<\mathbf{5 0}\end{array}$ & $\begin{array}{c}>=\mathbf{5 0} \\
\text { and } \\
<\mathbf{6 0}\end{array}$ & $\begin{array}{c}\boldsymbol{>}=\mathbf{6 0} \\
\text { and } \\
<\mathbf{7 0}\end{array}$ & $\begin{array}{c}>=\mathbf{7 0} \\
\text { and } \\
<\mathbf{8 0}\end{array}$ & $\begin{array}{c}>=\mathbf{8 0} \\
\text { and } \\
<\mathbf{9 0}\end{array}$ & $>=\mathbf{9 0}$ \\
\hline $\mathbf{1}$ & 3 & 15 & 22 & 22 & 25 & 18 & 2 & 1 & 0 \\
\hline $\mathbf{2}$ & 0 & 11 & 19 & 16 & 12 & 11 & 6 & 2 & 0 \\
\hline $\mathbf{3}$ & 8 & 19 & 27 & 20 & 38 & 14 & 5 & 3 & 0 \\
\hline $\mathbf{4}$ & 2 & 2 & 1 & 5 & 4 & 6 & 3 & 5 & 1 \\
\hline
\end{tabular}

Table 4: Distribution of female patients according to age range (years) Type $1=$ Anti-TPO + / Anti-TG = negative; Type $2=$ Anti-TPO $-/$ Anti-TG + ; Type 3= Anti-TPO+ / Anti-TG+; Type 4+ Anti-TPO- / Anti-TG- .

\begin{tabular}{|c|c|c|c|c|c|c|c|c|c|}
\hline & \multicolumn{9}{|c|}{ Age (Age range) } \\
\hline Type & $\begin{array}{c}>=10 \\
\text { and } \\
<20\end{array}$ & $\begin{array}{c}>=20 \\
\text { and } \\
<30\end{array}$ & $\begin{array}{c}>=\mathbf{3 0} \\
\text { and } \\
<40\end{array}$ & $\begin{array}{c}>=40 \\
\text { and } \\
<50\end{array}$ & $\begin{array}{l}>=50 \\
\text { and } \\
<60\end{array}$ & $\begin{array}{c}>=60 \\
\text { and } \\
<70\end{array}$ & $\begin{array}{c}>=70 \\
\text { and } \\
<80\end{array}$ & $\begin{array}{c}>=80 \\
\mathrm{e} \\
<90\end{array}$ & $>=90$ \\
\hline 1 & 0 & 1 & 5 & 0 & 8 & 2 & 0 & 0 & 0 \\
\hline 2 & 1 & 2 & 0 & 0 & 2 & 3 & 0 & 0 & 0 \\
\hline 3 & 0 & 2 & 1 & 4 & 4 & 2 & 3 & 0 & 0 \\
\hline 4 & 1 & 1 & 2 & 1 & 1 & 2 & 2 & 1 & 0 \\
\hline
\end{tabular}

Table 5: Distribution of male patients according to age range (years).

Type $1=$ Anti-TPO+/ Anti-TG - Type 3= Anti-TPO-/ Anti-TG+; Type 3+ Anti-TPO+/ Anti-TG+; Type 4= Anti-TPO- / Anti-TG -

\begin{tabular}{|c|c|c|c|c|}
\hline & \multicolumn{4}{|c|}{ Type of autoantibody expressed } \\
\hline Highest age & 1 & 2 & 3 & 4 \\
\hline Females & 80 & 82 & 85 & 95 \\
\hline Males & 63 & 69 & 76 & 85 \\
\hline Total & 80 & 82 & 85 & 95 \\
\hline
\end{tabular}

Table 6: Distribution of the 4 types of thyroiditis according to autoantibody expression in males and females and according to highest age (years).
Type1. Only Anti-TPO (+) autoantibody; Type 2. Only Anti-TG (+) autoantibody; Type 3. Anti-TPOand Anti-TG (+) autoantibodies; Type 4. Anti-TPO-/ Anti-TG-autoantibodies.

\begin{tabular}{|c|c|c|c|c|}
\hline & \multicolumn{4}{|c|}{ Type of autoantibody expressed } \\
\hline Minimum age & 1 & 2 & 3 & 4 \\
\hline Females & 15 & 25 & 11 & 17 \\
\hline Males & 24 & 14 & 27 & 18 \\
\hline
\end{tabular}

Table 7: Distribution of the 4 types of thyroiditis according to autoantibody expressed and the minimum age (in years) observed in the 2 sexes.

Type1. Only Anti-TPO (+) autoantibody; Type 2. Only Anti-TG (+) autoantibody; Type3. Anti-TPO and Anti-TG (+) autoantibodies; Type 4. Anti-TPO-/ Anti-TG-

\begin{tabular}{|c|c|c|c|c|c|}
\hline TYPE & $\begin{array}{c}\text { Patients } \\
\text { with TSH } \\
\text { analyzed }\end{array}$ & $\begin{array}{c}\text { Mean } \\
\text { TSH }\end{array}$ & $\begin{array}{c}\text { Standard } \\
\text { deviation of } \\
\text { TSH }\end{array}$ & $\begin{array}{c}\text { Minimum } \\
\text { TSH } \\
\text { value }\end{array}$ & $\begin{array}{c}\text { Maximum } \\
\text { TSH value }\end{array}$ \\
\hline 1 & 123 & 6.5 & 7.8 & 0.61 & 45 \\
\hline 2 & 85 & 6.1 & 10.6 & 0.83 & 67.64 \\
\hline 3 & 150 & 10.4 & 18.7 & 0.50 & 136.8 \\
\hline 4 & 40 & 13.8 & 15.5 & 5.01 & 71.4 \\
\hline $\begin{array}{c}\text { General } \\
\text { total }\end{array}$ & 398 & 8.6 & 14.3 & 0.50 & 136.8 \\
\hline
\end{tabular}

Table 8: Distribution of TSH values (IU/L) in the patients studied according to the type of autoantibody present. $\mathrm{p}=00043$.

Type 1= Anti-TPO+/ Anti-TG- ; Type 2= Anti-TPO-/ Anti-TG+; Type 3= Anti-TPO+/ Anti-TG+; Type 4= Anti-TPO-/ Anti-TG-

\begin{tabular}{|c|c|c|c|c|c|}
\hline Type E & $\begin{array}{c}\text { Patients } \\
\text { with T4L } \\
\text { analyzed }\end{array}$ & $\begin{array}{c}\text { Mean } \\
\text { T4L }\end{array}$ & $\begin{array}{c}\text { Standard } \\
\text { deviation } \\
\text { of T4L }\end{array}$ & $\begin{array}{c}\text { Minimum } \\
\text { T4L value }\end{array}$ & $\begin{array}{c}\text { Maximum } \\
\text { T4L value }\end{array}$ \\
\hline 1 & 100 & 1.06 & 0.28 & 0.82 & 1.45 \\
\hline 2 & 76 & 1.10 & 0.19 & 0.88 & 1.60 \\
\hline 3 & 129 & 1.05 & 0.42 & 0.80 & 1.90 \\
\hline 4 & 40 & 0.98 & 0.25 & 0.83 & 1.48 \\
\hline $\begin{array}{c}\text { General } \\
\text { total }\end{array}$ & 345 & 1.06 & 0.32 & 0.80 & 1.90 \\
\hline
\end{tabular}

Table 9: Distribution of free T4 in the patients studied according to type of autoantibody present.

Type 1= Anti-TPO+/ Anti-TG-; Type 2= ANTI TPO- / Anti-TG+; Type 3= Anti-TPO+/ Anti-TG-; Type 4= Anti-TPO- / Anti-TG -

\begin{tabular}{|c|c|c|c|c|c|}
\hline Type & $\begin{array}{c}\text { Patients with } \\
\text { analyzed TG }\end{array}$ & $\begin{array}{c}\text { Mean } \\
\text { TG }\end{array}$ & $\begin{array}{c}\text { Standard } \\
\text { deviation } \\
\text { of TG }\end{array}$ & $\begin{array}{c}\text { Minimum } \\
\text { TG value }\end{array}$ & $\begin{array}{c}\text { Maximum } \\
\text { TG value }\end{array}$ \\
\hline 1 & 67 & 62.6 & 98.5 & 0.8 & 500.0 \\
\hline 2 & 61 & 29.0 & 43.6 & 1.0 & 259.0 \\
\hline 3 & 112 & 42.0 & 69.0 & 0.3 & 348.0 \\
\hline 4 & 36 & 56.6 & 76.4 & 1.0 & 302.0 \\
\hline $\begin{array}{c}\text { General } \\
\text { total }\end{array}$ & 276 & 46,0 & 74,6 & 0.3 & 500.0 \\
\hline
\end{tabular}

Table 10: Distribution of thyroglobulin (TG) values in the 4 types of thyroiditis

$\mathrm{p}=0.0553$; Type 1= Anti-TPO+ / Anti-TG- ;ype 2= Anti-TPO- $/$ Anti-TG+; Type 3= Anti-TPO+/ Anti-TG+; Type 4= Anti-TPO- / Anti-TG- 


\begin{tabular}{|c|c|c|c|c|c|}
\hline \multirow{2}{*}{$\begin{array}{c}\text { Findings } \\
\text { US }\end{array}$} & \multicolumn{5}{|c|}{ Patients (Total and \%) and type of antibody present } \\
\hline & Type 1 Total / \% & Type 2 Total / \% & Type 3 Total / \% & Type 4 Total / \% & Statistical significance $(p)$ \\
\hline No nodules & $7 / 56.5$ & $33 / 38$ & $72 / 48$ & $12 / 30$ & 0.2310 \\
\hline Calcifications + & $5 / 4$ & $7 / 8.2$ & $4 / 2.7$ & $3 / 7.5$ & 0.2555 \\
\hline TIRADS $\geq 4$ & $4 / 3.2$ & $1 / 1.2$ & $1 / 0.7$ & $2 / 5$ & \\
\hline Hypo Echogenic & $8 / 30.6$ & $32 / 37.6$ & $44 / 29.3$ & $15 / 37.5$ & 0.300 \\
\hline Reg Contours & $33 / 26.6$ & $30 / 35.3$ & $43 / 28.7$ & $14 / 35$ & 0.7350 \\
\hline Multinodularity & $33 / 26.6$ & $31 / 36.5$ & $35 / 23.3$ & $9 / 22.6$ & $<0.001$ \\
\hline Sol Nod+Cystic N & $2 / 1.6$ & $4 / 4.7$ & $4 / 2.7$ & $8 / 20$ & \\
\hline Isolated Sol Nod & $7 / 7.6$ & $6 / 7.1$ & $10 / 6.7$ & $3 / 7.5$ & 0.9721 \\
\hline Pseudonodul & $4 / 3.2$ & $3 / 3.5$ & $6 / 4$ & & \\
\hline Cysts & $1 / 0.8$ & $3 / 3.5$ & $4 / 2.7$ & $2 / 5$ & 0.4366 \\
\hline Microcysts & $2 / 1.6$ & $2 / 2.4$ & $3 / 2$ & $3 / 2$ & 0.2358 \\
\hline Increased Vasc & $9 / 7.3$ & $5 / 5.9$ & $8 / 5.3$ & $2 / 5$ & 0.244 \\
\hline Heterogeneity & $121.0 / 97.6$ & 82 / 96.5 & 145 / 96.7 & 39 / 97.5 & 0.999 \\
\hline
\end{tabular}

Table 11: Total and percent values of the ultrasound changes detected in the thyroids analyzed according to the 4 types of autoantibodies expressed in each organ.

US= Ultrasound; Echogenic= Echogenicity; Reg= Regular; Nod Sol + Cystic N = Solid nodule + Cystic nodule in the same gland; Pseudonodul = Pseudonodularity; Vasc $=$ Vascularization

Type 1= Anti-TPO+/ Anti-TG-; Type 2= Anti-TPO- / Anti-TG+; Type 3= Anti-TPO+/ Anti-TG+; Type 4= Anti-TPO- / Anti-TG-

\section{Conclusions}

The credit for the present study resides in its sample size and in some of the changes observed, which suggest some peculiarities of the laboratory and ultrasound findings. The possibility of additional complementary statistical analyses is also suggested [32].

\section{Acknowledgments}

To Professor Renata Dellalibera Joviliano for her suggestions.

\section{References}

1. Hashimoto H. Zur Kenntniss der lymphomatosen Veranderung der Schilddruse (struma lymphomatosa). Arch Klin Chir. 1912; 97:219.

2. Skillern PG, Crile G Jr, McCullagh EP, et al. Struma lymphomatosa: Primary thyroid failure with compensatory thyroid enlargement. J Clin Endocrinol Metab. 956;16(1):35-54.

3. PARIS, J., et al. The effect of iodides on Hashimoto's thyroiditis. J Clin Endocrinol Metab, 1961, 21, p. 1037.

4. Bianco AC Fisiologia da glândula tireoide. In: Rosa JC, Romão LA (eds) Glândula Tireoide: Funções e Disfunções- Diagnóstico e Tratamento.2001. Second edition. Lemos, São Paulo, Brazil, pp33-46.

5. Lamberger BA. Endemic goiter- iodine deficiency disorders. Ann Med. 1991; 23:367-372.

6. Sakata S, Matsuda M, Ogwa T, et al. Prevalence of thyroid hormone autoantibodies in healthy subjects. Clin Endocrinol. 1994; 41(3):365-370.

7. Takasu N, Yamada T, Takasu M, et al. Disappearance of thyrotropin-blocking antibodies and spontaneous recovery from hypothyroidism in autoimmune thyroiditis. $\mathrm{N}$ Engl $\mathrm{J}$ Med.1992; 326:513-518.

8. Williams DE, Le SN Godlewska, Hoke DE, et al. Thyroid peroxidase as an autoantigen in Hashimoto's disease structure function and antigenicity. Horm Met Res. 2018; 50(12):908-921.

9. Salvatore D, Davies TE, Schlumberger MJ, et al. Thyroid physiology and diagnostic evaluation of patients with thyroid disorders. In: Larsen PR (ed). Williams Textbook of Endocrinology. 12a ed,2011; Philadelphia: WB Saunders Co pp327-337.

10. Tunbridge WM, Evered DC, Hall R, et al. The spectrum of thyroid disease in a community the Whickham Survey. Clin Endocrinol (Oxf). 1977; 7(6):481-93.

11. Canaris GJ, Manowitz NR, Mayor G, Ridgway EC. The Colorado thyroid disease prevalence study. Arch Intern Med. 2000; 160(4); 526-93.

12. Alves MLD, Gabarra MHC. Evaluation of thyroid function in a group of recently diagnosed patients with thyroid diseases followed up at the endocrinology outpatient clinic of the University of Ribeirão Preto (UNAERP)- São Paulo Brazil. J Endocrinol. 2017; 1(1)000102.

13. Sichieri R, Baima J, Henriques J, et al. Prevalence of thyroid disease and positive antitireoperoxidase among 1500 women 35 years old: a population -based survey in the city of Rio de Janeiro, Brazil. Thyroid. 2005, 15(Supp1): S-42 abs 118.

14. Gurnell M, Halsall DJ, Chatterine VK. What should be done when thyroid function tests do not make sense? Clin Endocrinol. 2007; 74(6):673-678.

15. Dufour DR. Laboratory tests of thyroid function: uses and limitations. Endocrinol Metab Clin North Am. 2007; 36(3): 579594.

16. YO WS, Chung HK, Recent Advances in autoimmune thyroid diseases. Endocrinol Metab (Seoul). 2016; 31(3):379-385.

17. Vaisman M. Hipotireoidismo em situações especiais: Hipotireoidismo e o idoso. In: Programa de atualização em doenças da tireoide da SBEM 2009; 3:4-5.

18. Faggiano A, Del Prete M, Marciello F, et al. Thyroid diseases in elderly. Minerva Endocrinol. 2011; 36(3):211-231.

19. Gesing A, Levinsk A, Karbownick-Lewinska M. The Thyroid gland and the process of aging: what is new. Thyroid Research. 2012; 5(1):16

20. Nagaratnam N, Nagaratanam K, Cheuk G. Thyroid disease in the older patient. Geriatric Diseases. 2017; 92(5):1715-23

21. Sweeny LB, Stewart C, Gaitonde DY. Thyroiditis: an integrated approach. Am Fam Physician. 2014; 90(6): 389-396.

22. Caturegli P, Remigis A, Rose NR. Hashimoto Thyroiditis: clinical and diagnostic criteria. Autoimmun Rev. 2014; 13:391-7.

23. Freitas MC, Torres MR, Nóbrega MBM, et al. Tireoidites/ Diagnóstico e Tratamento. In: Endocrinologia clínica. Ed. Lúcio Vilar, 6a edição. Guanabara Koogan, 2017. 
24. Wiersinga WM. Clinical relevance of environment factors in the pathogenesis of autoimmune thyroid disease. Endocrinol Metab (Seoul). 2016; 31(2):213-22.

25. Tahboub R, Arafat BM. Sex steroids and the thyroid. Best Pract Res Clin Endocrinol Metab. 2009; 23(6):769-780.

26. Careila C, Mazzioni G, Morisco F. The addition of ribavirin to interferon-alpha therapy in patients with hepatitis $\mathrm{C}$ virus related chronic hepatitis does not modify the thyroid autoantibody pattern, but increases the risk of developing hypothyroidism. Eur J Endocrinol. 2002; 46:743-749.

27. Betterle C, Del Pita C, Manter F, et al. Autoimmune adrenal insufficiency and autoimmune polyendocrine syndromes autoantibodies autoantigens, and their applicability in diagnosis and disease prediction. Endocr Rev, 2002; 23:327-64.
28. Singer PA. Thyroditis: acute, subacute and chronic. Med Clin North Am.1991; 75:61-77.

29. Ling SM. Euthyroid goiters in children. Correlation of needle biopsy with other clinical and laboratory findings in chronic lymphocytic thyroiditis and simple goiter. Pediatrics. 1969; 44(5):695-708.

30. Fish A, Fish S. Hashimoto thyroditis is a risk factor for thyroid cancer. Thyrodology 2013;31(8):333-335.

31. Silva de Moraes W, Stear G,Wang Z, et al. The impact of Hashimoto thyroiditis on thyroid nodule cytology and risk of thyroid cancer. J Clin Endocrinol. 2019; 3:791-800.

32. Baretić M. 100 years of Hashimoto thyroiditis, still an intriguing disease. Acta Med Croatica. 2011; 65(5):453-457. 